\title{
The Implication of Channel Discrepancy in a Dual-Channel Supply Chain
}

\author{
Zhenyang Pi ${ }^{1}{ }^{1}$ and Weiguo Fang $\mathbb{D}^{1,2}$ \\ ${ }^{1}$ School of Economics and Management, Beihang University, Beijing 100083, China \\ ${ }^{2}$ Key Laboratory of Complex System Analysis, Management and Decision (Beihang University), Ministry of Education, \\ Beijing 100083, China \\ Correspondence should be addressed to Weiguo Fang; wgfang@buaa.edu.cn
}

Received 18 July 2020; Revised 17 September 2020; Accepted 21 January 2021; Published 31 January 2021

Academic Editor: Zhile Yang

Copyright (c) 2021 Zhenyang Pi and Weiguo Fang. This is an open access article distributed under the Creative Commons Attribution License, which permits unrestricted use, distribution, and reproduction in any medium, provided the original work is properly cited.

\begin{abstract}
This paper studies the implication of channel discrepancy between the retail and direct channels in a dual-channel supply chain consisting of one common retailer and two manufacturers in which the manufacturers may have different market powers. Each manufacturer provides a substitutable product and opens an online channel to customers directly. We develop an analytical model to derive the optimal pricing strategies by using game theory and the backward induction method, and we examine related properties under three market power structures while considering channel discrepancy, including the Nash equilibrium, the Manufacturers leader Stackelberg, and the $M_{1}$ leader Stackelberg models (denoted as the N, MS, and $\mathrm{M}_{1} \mathrm{~S}$ models, respectively). Numerical simulations are examined to reveal and verify the effect of channel discrepancy on optimal prices, demands, and profits. We find that a higher level of channel discrepancy induces higher prices, demands, and profits for each member in both channels, while this kind of stimulating impact for the leader manufacturer who obtains a higher level of channel discrepancy will be more significant than it is for the other members in the three models. In addition, the profit of the supply chain in the $\mathrm{N}$ model is always higher than it is in the MS model, while it may be higher or lower than it is in the $M_{1} S$ model depending on the level of channel discrepancy.
\end{abstract}

\section{Introduction}

Because information technology (IT) has developed rapidly, many manufacturers can sell products through their own direct (online) channels conveniently, which increases competition with the traditional brick-and-mortar retail channel $[1,2]$. The competition between retail and direct channels is distinct for different manufacturers, who provide various products or services to adjust their direct channel strategies $[3,4]$. For a manufacturer selling products through the retail and direct channels, we define the channel discrepancy of the manufacturer as the competition between these two channels. Different direct channel strategies may have different impacts on each channel member. For example, Dell offers customized products through its online channel, which allows customers to determine the configuration level of their computers and gives them more room for choice, while other manufacturers (e.g., Xiaomi or Huawei) offer the same standardized products in both the direct and the retail channels. Many examples also suggest that the manufacturer can change its channel discrepancy through other nonprice factors. For instance, most apparel companies, including Uniqlo, ZARA, and H\&M, promise 30-day no-reason return services in their online stores if the product is not damaged and if the return does not affect secondary sales. Another example is that many beauty enterprises in the United States such as Kiehl's, Clinique, and Este Lauder send free samples to new members of their online sites so they can try and experience their products. Although the existence of these nonprice discrepancies between the direct and retail channels cannot determine the price of products directly, it has a great effect on the 
relationship between price and demand in the market. Specifically, when the manufacturer sells the same products to customers through the retail and direct channels, channel discrepancy between these two channels means that the customers' channel choice is more likely to be affected by the price difference between the retail and direct channels. A higher retail price or a lower direct price leads customers to become more likely to choose the direct channel, thus inducing a higher demand for the direct channel, and vice versa. However, it remains unclear how the channel discrepancy of manufacturers affects the dual-channel supply chain operations when considering such a phenomenon.

As IT, big data, and artificial intelligence grow, the interaction increases between manufacturers and customers, which makes it easy for a manufacturer to obtain demand information for customers and to develop specific service policies in its direct channel. Hence, compared with the traditional retail channel, a manufacturer can easily increase its channel discrepancy at a low cost. For example, when a manufacturer pays more attention to its direct channel construction-such as by increasing product diversity, reducing delivery time, and providing better after-sale service-the channel discrepancy of a manufacturer between the retail and direct channels will become greater. By focusing on this phenomenon in the market, we develop a mathematical model in a dual-channel supply chain consisting of two manufacturers and one common retailer (denoted as $M_{1}, M_{2}$, and $R$, respectively), in which the two manufacturers sell substitutable products from their own direct channels and a common retail channel, to explore the following two questions. (1) How does the manufacturer's channel discrepancy affect each channel member's optimal strategies, demands, and profits? and (2) How does the market power structure affect the equilibrium results and profits of the channel members? In general, the market power structure of a supply chain may be different when some of the channel members have more/less power than others in the market. To examine how the market power structure affects the dualchannel supply chain operations when considering the manufacturer's channel discrepancy, we discuss three different market power structures in the supply chain, namely, the Nash equilibrium, the Manufacturers leader Stackelberg, and the $M_{1}$ leader Stackelberg models (denoted as the N, MS, and $\mathrm{M}_{1} \mathrm{~S}$ models, respectively). In the $\mathrm{N}$ model, each channel member has the same market power, while in the MS model, the two manufacturers have the same market power and it is greater than the retailer's market power. In fact, both the $\mathrm{N}$ and the MS models are common in the literature and have been widely explored by many studies [5-7], while little literature explores the $M_{1} S$ model, in which $M_{1}$ as a leader has more power than another manufacturer and the retailer. Recently, Wang et al. [8] studied one manufacturer leader Stackelberg model under a dual-channel supply chain. However, they considered complementary products, and, in their model, only one manufacturer opened a direct channel. In the real market, the $\mathrm{M}_{1} \mathrm{~S}$ model is also common. For example, Apple, as a leading company in the electronic product industry, can be seen as a Stackelberg leader when providing substitute products to the market and competing with other companies (such as Xiaomi or Nokia). Therefore, exploring the effect of the market power structure on dualchannel operations is necessary.

Previous studies based on similar assumptions and related models mainly focused on price issues. For instance, Choi [7] adopted the linear and nonlinear demand functions to solve the equilibrium prices for three cases: the Vertical Nash, Retailer Stackelberg, and Manufacturer Stackelberg models. Wei et al. [9] examined the pricing problems in five decentralized decision cases while considering different market power structures. Jena and Sarmah [10] studied the price and service competition between two remanufacturing firms who sell their substitutable products through a common retailer and provide service directly to the end customers. However, none of these studies have considered the effect of the manufacturer's channel discrepancy on optimal strategies and profits. As an extension of the previous studies, we explore the equilibrium decisions of each channel member in three different power structures. We consider the price competitions not only between the retail and direct channels but also between two different direct channels with different channel discrepancies. Numerical experiments are also examined to analyze the impact of the manufacturer's channel discrepancy on the optimal strategies and profits. We find that each equilibrium result or profit increases in the channel discrepancy of the manufacturer, and the effect of one manufacturer's channel discrepancy on this manufacturer is higher than it is on another manufacturer. More interestingly, compared with the Nash equilibrium model, the profit is always worse if the two manufacturers, as leaders, hold the same market power structure, while for a model in which one manufacturer has more power than another, the profit may be better at a higher level of channel discrepancy.

The remainder of the paper proceeds as follows: In Section 2, we review the literature on the dual-channel supply chain. Section 3 presents descriptions and the assumptions of the mathematical model in a dual-channel supply chain. In Section 4, we derive the optimal strategies and analyze the relevant properties under three market power structures. Section 5 numerically reveals and verifies the effect of channel discrepancy on prices, demands, and profits. Section 6 provides the managerial insights of this study. Section 7 concludes our work and findings.

\section{Literature Review}

Two streams of the literature relate to this study. The first is the pricing strategy in a dual-channel supply chain, and the second is related to the competition between two manufacturers with a common retailer.

The pricing strategy is the main research direction in the realm of a dual-channel supply chain. Chiang et al. [1] constructed a pricing game model between a manufacturer and an independent retailer to investigate the supply chain design problem. Cattani et al. [11] studied the pricing strategies used when a manufacturer added a direct channel to compete with its traditional channel partner. Using game theory, Park and Keh [12] explored and compared the 
equilibrium pricing decisions in three scenarios: direct channel only, retail channel only, and both channels. Huang and Swaminathan [13] examined the optimal pricing strategies when a product is sold on a dual-channel supply chain. A large number of articles in this area are based on developing a pricing strategy to explore the problems of lead time [14-16], green supply [17-19], retail service [20-22], free-riding [23-25], inventory [26], return policy [27], and channel strategy [28-30]. For example, He et al. [26] explored the pricing and inventory decisions of deteriorating products in a dual-channel supply chain. Concentrating on new and remanufactured products in a dual-channel closedloop supply chain, He et al. [29] investigated pricing and channel structure strategies. He et al. [27] discussed the return policies of a dual-channel supply chain. Ren et al. [31] focused on unidirectional transshipment strategies between the retail and direct channels to study dual-channel operations. Hua et al. [14] studied the price and lead-time strategies in a dual-channel supply chain and explored the impact of the delivery lead time on the channel members' pricing decisions. Yao and Liu [32] considered the price competition in a dual-channel supply chain under the Bertrand and Stackelberg price competition models, in which the retailer provides value-added services to mitigate the channel conflict. Chen et al. [33] analyzed price and quality decisions in dual-channel supply chains. Xiao and Shi [34] investigated pricing and channel priority strategies in the presence of a supply shortage caused by random yields. However, most of the above literature mainly concentrates on the price competition between the manufacturer's direct channel and the retailer's retail channel, while few studies focus on channel discrepancy and its impact on the channel member's strategies if two manufacturers both open their own direct channels.

Some studies also focus on the competition between two manufacturers with a common retailer. For instance, Choi [7] adopted linear and nonlinear demand functions to study the channel competition between two manufacturers in three different power structures. Lu et al. [4] investigated the competition for manufacturer services and retail prices in a supply chain in which two manufacturers provide the service directly and the product indirectly. Ma et al. [5] examined the dominant strategies taken by a leading manufacturer to maintain its dominance in a dual-channel supply chain. Kurata et al. [35] investigated the pricing strategies in multiple distribution channels under competition between a national and a store brand. The research most relevant to our study is that of Choi [7] and Wei et al. [9], who examined the pricing and channel strategies of a supply chain in different power structures. As an extension of Wei et al. [9], Zhao et al. [36] investigated the complementary product and channel competition in a dual-channel supply chain, in which one manufacturer opens its direct channel. Based on the same model, Wang et al. [8] explored the pricing and service decisions of complementary products in a dualchannel supply chain in which one manufacturer opens its direct channel. However, studies of this kind of structure, consisting of two manufacturers and one common retailer in which only one of the manufacturers opens its direct channel, have lagged behind real developments. On the one hand, as information technology develops, a manufacturer can easily open its direct channel. On the other hand, a manufacturer will not hesitate to open its direct channel if its competitors have done so. To fill this gap in the research, this paper assumed that both manufacturers open their direct channels and act through a common retailer to sell products to customers. We explored the effect of the manufacturer's channel discrepancy on each member's optimal pricing strategy and profit. In addition, we explore the impact of the market power structure on the equilibrium result when considering the channel discrepancy of manufacturers. The previous studies mainly focus on the Nash equilibrium model [7] or the Manufacturers leader Stackelberg model [4], in which manufacturers have the same market power, but these studies pay little attention to the situation in which manufacturers may have different market powers, especially when both manufacturers open their own direct channels. Table 1 explains the location of our work in the literature.

\section{Model Descriptions and Assumptions}

We consider a supply chain consisting of three independent entities in a single period, that is, two manufacturers and one common retailer (denoted as $M_{1}, M_{2}$, and $R$, respectively). We assume that each manufacturer produces a product, and the two products are substitutable (denoted as product 1 and product 2, respectively). Each product is distributed from one manufacturer to consumers through a common retail channel and a direct channel. Currently, as e-commerce is booming, big manufacturers are shifting their direct channels to online configurations. Hence, in this paper, we consider the online channel as a direct channel. The retailer, as an independent entity, purchases products from the two manufacturers and sells them to customers. The model structure for a dual-channel supply chain is shown in Figure 1.

For product $i$ (where $i=1,2$ ), the direct, retail, and wholesale prices are expressed as $P_{i 1}, P_{i 2}$, and $W_{i}$, respectively. We use $D_{i j}$ to represent the demand for product $i$ in channel $j$, where $j=1$ and $j=2$ represent the direct and retail channels, respectively. Linear demand functions have been adopted extensively in fields of supply chain management $[2,37-39]$. Therefore, for $M_{1}$ and $M_{2}$, the demand functions of different channels can be expressed as the following linear functions:

$$
\left\{\begin{array}{l}
D_{11}=\varphi a_{1}-\alpha_{1} P_{11}+\beta_{1} P_{12}+\gamma_{1} P_{21} \\
D_{21}=\varphi a_{2}-\alpha_{2} P_{21}+\beta_{2} P_{22}+\gamma_{2} P_{11} \\
D_{12}=(1-\varphi) a_{1}-\alpha_{1} P_{12}+\beta_{1} P_{11}+\gamma_{1} P_{22} \\
D_{22}=(1-\varphi) a_{2}-\alpha_{2} P_{22}+\beta_{2} P_{21}+\gamma_{2} P_{12}
\end{array}\right.
$$

where $a_{1}$ and $a_{2}$ represent the base level demand on products 1 and 2 , respectively, in the market (i.e., the potential demand if the product is free of charge). $\varphi$ measures the rate at which consumers prefer the direct channel. $\alpha_{i}$ is the selfprice elasticity coefficient. $\beta_{i}$ is the channel discrepancy of $M_{i}$, which usually reflects the extent to which the goods sold 
TABLE 1: Location of our work in the literature.

\begin{tabular}{|c|c|c|c|c|}
\hline & \multirow{2}{*}{ Channel discrepancy } & \multirow[t]{2}{*}{ Number of direct channels } & \multicolumn{2}{|c|}{$\begin{array}{c}\text { Manufacturers' market } \\
\text { power }\end{array}$} \\
\hline & & & Same & Different \\
\hline Lu et al. [4]; Choi [7] & & 0 & $\sqrt{ }$ & \\
\hline Pi et al. [2]; He et al. [26] & & 1 & & \\
\hline Ma et al. [5]; Zhao et al. [6] & & 0 & $\sqrt{ }$ & $\sqrt{ }$ \\
\hline Wang et al. [8]; Zhao et al. [36] & & 1 & $\sqrt{ }$ & $\sqrt{ }$ \\
\hline This study & $\sqrt{ }$ & 2 & $\sqrt{ }$ & $\sqrt{ }$ \\
\hline
\end{tabular}

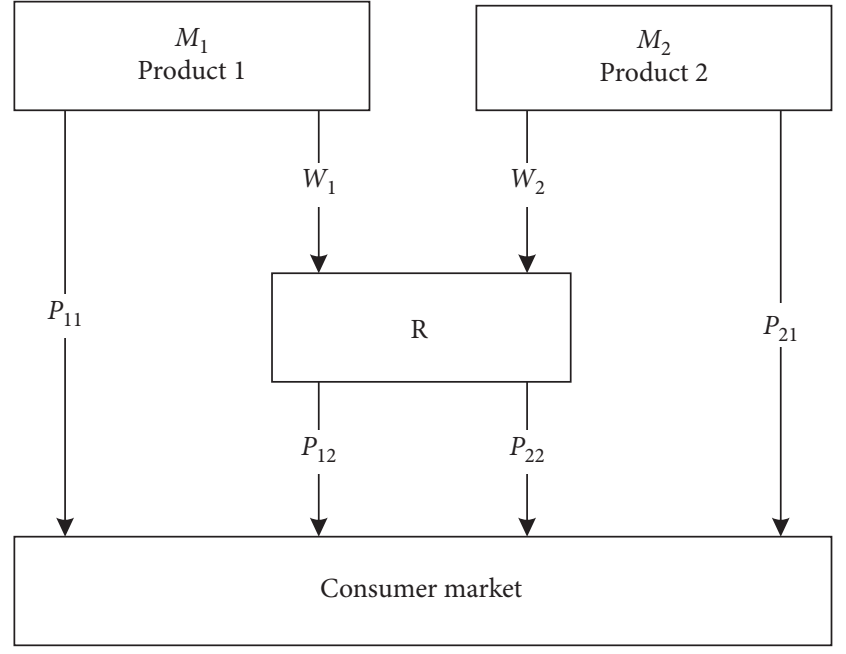

Figure 1: Dual-channel supply chain model.

via the retail and direct channels are substitutable. $\gamma_{i}$ depicts the competition between the two substitutable products in the same kind of distribution channel. For the sake of simplicity, we assume $\alpha_{1}=\alpha_{2}=\alpha$ and $\gamma_{1}=\gamma_{2}=\gamma$ to concentrate our attention on the implications of channel discrepancy. Many studies have shown that relaxing the assumption to differentiate these parameters does not change the main conclusions but increases the complexity of the analysis $[2,6,23]$. Therefore, we follow this assumption in our analysis.

We explain the demand model (i.e., equation (1)) as follows. Due to consumption habits, age, education, conversion cost, and other factors, customers usually have certain preferences for specific products (or producers) and/ or purchase channels. For example, some customers show certain brand loyalty and are more inclined to buy the products of a certain brand or manufacturer. Some customers enjoy going to the retail store to buy the product they want because, by doing so, they can have more direct experience with the product. Finally, some younger or busier customers may prefer to shop online.

Take demand $D_{11}$ as an example, which represents the demand to purchase product 1 through the direct channel. Intuitively, the four prices $-P_{11}, P_{12}, P_{21}$, and $P_{22}$-influence $D_{11}$. Considering that customers usually prefer specific products or/and channels, the influence of these four factors can be divided into three levels from high to low. The first-level factor is naturally the sales price of product 1 in the direct channel, $P_{11}$. The second-level factors are $P_{12}$ (adherence to product 1 with the shifted channel) and $P_{21}$ (adherence to the direct channel with the shifted product). The third-level factor is $P_{22}$ because both the product and the channel have changed. In comparison, among the four prices, $P_{22}$ has the lowest impact on $D_{11}$. For the simplicity of the model and the subsequent analysis, the influence of $P_{22}$ is ignored in $D_{11}$. Similarly, $P_{12}$ is not considered in $D_{21}, P_{21}$ is ignored in $D_{12}$, and $P_{11}$ is ignored in $D_{22}$.

In addition, we add three supplementary assumptions to our model.

Assumption 1. $0 \leq c_{i}<W_{i}<P_{i 1}, P_{i 2}$;

Assumption 2. $0<\beta_{i}, \gamma<\alpha$ and $\beta_{i}+\gamma<\alpha$;

Assumption 3. $K_{2}^{2}-K_{1} K_{4}<0$; where $i=1,2$ and $K_{1}, K_{2}$, and $K_{4}$ are shown in Appendix A.

Assumption 1 ensures that the retailer and two manufacturers are willing to enter the market and the retailer will not purchase the product from the direct channel of any manufacturer. Assumption 2 implies that the self-price effect on the demand is stronger than the cross-channel effect, the cross-product effect, and their joint effect, which ensures the existence of the equilibrium results and that they are consistent with the real market.

Enterprises usually have multiple pursuits such as seeking profits for the enterprise, seeking wealth for shareholders, seeking welfare for employees, and creating employment for the society among which, for a for-profit enterprise, profit maximization is the primary goal; otherwise, other goals are difficult to achieve. This paper only studies the operation strategy of the supply chain from the perspective of profit. In the $M_{1} S$ model, $M_{1}$ has the most market power compared with the other two members and can be regarded as the industry leader. Therefore, $M_{1}$ has the motivation and ability to pursue its own profit maximization. By considering such motivation of the leader manufacturer, we introduce Assumption 3 to ensure the existence and uniqueness of the optimal solution when $M_{1}$ maximizes its own profit (see the proof of Proposition 5 in Appendix B).

Assume the unit production costs of the two products are represented as $c_{1}$ and $c_{2}$. Furthermore, we do not consider the manufacturer's and retailer's operation costs, we assume that the quantity of each product can meet market demand, and we assume there is no inventory 
holding cost for each channel member. Therefore, the payoff of $M_{1}$ includes the direct channel revenue $\left(P_{11}-c_{1}\right) D_{11}$ and the wholesale revenue $\left(W_{1}-c_{1}\right) D_{12}$. The profit for $M_{1}$ (denoted as $\pi_{1}$ ) can be expressed as

$$
\pi_{1}=\left(P_{11}-c_{1}\right) D_{11}+\left(W_{1}-c_{1}\right) D_{12} .
$$

Similarly, for $M_{2}$ and $R$, their payoffs (denoted as $\pi_{2}$ and $\pi_{r}$, respectively) are

$$
\begin{aligned}
& \pi_{2}=\left(P_{21}-c_{2}\right) D_{21}+\left(W_{2}-c_{2}\right) D_{22}, \\
& \pi_{r}=\left(P_{12}-W_{1}\right) D_{12}+\left(P_{22}-W_{2}\right) D_{22} .
\end{aligned}
$$

\section{Theoretical Analysis and Results}

To explore how the market power structure impacts the optimal strategies of each channel member, we discuss three different models in the following parts, that is, the Nash equilibrium model ( $\mathrm{N}$ model), the Manufacturers leader Stackelberg model (MS model), and the $M_{1}$ leader Stackelberg model $\left(\mathrm{M}_{1} \mathrm{~S}\right.$ model). All of the equilibrium results are derived by using game theory and the backward induction method. The superscripts for $N, \mathrm{MS}$, and $\mathrm{M}_{1} \mathrm{~S}$ are adopted to distinguish the equilibrium results from the different models.

4.1. Nash Equilibrium Model. When the market powers between the retailer and the manufacturers are comparable, the Nash equilibrium model will exist. In this model, each channel member makes its own optimal pricing decisions simultaneously and independently. The optimal strategies of each member can be formulated as follows:

$$
\left\{\begin{array}{l}
\max _{P_{11}, W_{1}} \pi_{1}=\left(P_{11}-c_{1}\right) D_{11}+\left(W_{1}-c_{1}\right) D_{12}, \\
\max _{P_{21}, W_{2}} \pi_{2}=\left(P_{21}-c_{2}\right) D_{21}+\left(W_{2}-c_{2}\right) D_{22}, \\
\max _{P_{12}, P_{22}} \pi_{r}=\left(P_{12}-W_{1}\right) D_{12}+\left(P_{22}-W_{2}\right) D_{22} .
\end{array}\right.
$$

To obtain the maximum profits, the retailer will determine optimal retail prices $P_{12}^{N *}$ and $P_{22}^{N *}$, while $M_{1}$ and $M_{2}$ will determine optimal wholesale prices $W_{1}^{N *}$ and $W_{2}^{N *}$ and optimal direct prices $P_{11}^{N *}$ and $P_{21}^{N *}$. The optimal pricing strategy in the $\mathrm{N}$ model is given in Proposition 1.

Proposition 1. The optimal price strategy in the Nash equilibrium model can be formulated as

$$
\left(P_{11}^{N *}, W_{1}^{N *}, P_{21}^{N *}, W_{2}^{N *}, P_{12}^{N *}, P_{22}^{N *}\right)^{T}=-A_{1}^{-1} B_{1},
$$

where $A_{1}$ and $B_{1}$ are shown in Appendix $A$.

Proofs for Proposition 1 and the other propositions are shown in Appendix B.

Proposition 1 indicates that, for each manufacturer, its profit is jointly concave with its wholesale and direct prices. The equilibrium wholesale and direct prices of one manufacturer depend not only on its production costs but also on the production costs of the other manufacturer. Furthermore, the retailer's profit is jointly concave with the retail prices of the two products and is deeply affected by the potential demand for each product.

4.2. Manufacturers Leader Stackelberg Model. The Manufacturers leader Stackelberg model obtains some powerful manufacturers, such as Apple, Dell, and Ford, whose market powers are far greater than those of their retailers. In this model, the two manufacturers first choose their wholesale and direct prices simultaneously and independently, and then the retailer chooses its retail prices for the two products. The MS model is formulated as follows:

$$
\left\{\begin{array}{l}
\left\{\begin{array}{l}
\max _{P_{11}, W_{1}} \pi_{1}\left(P_{12}^{*}, P_{22}^{*}\right)=\left(P_{11}-c_{1}\right) D_{11}+\left(W_{1}-c_{1}\right) D_{12}, \\
\max _{P_{21}, W_{2}} \pi_{2}\left(P_{12}^{*}, P_{22}^{*}\right)=\left(P_{21}-c_{2}\right) D_{21}+\left(W_{2}-c_{2}\right) D_{22},
\end{array}\right. \\
\text { where }\left(P_{12}^{*}, P_{22}^{*}\right) \text { are derived from solving, } \\
\max _{P_{12}, P_{22}} \pi_{r}=\left(P_{12}-W_{1}\right) D_{12}+\left(P_{22}-W_{2}\right) D_{22} .
\end{array}\right.
$$

Given the two manufacturers' direct and wholesale prices, the response function of the retailer can be formulated as in Proposition 2.

Proposition 2. From the retailer's payoff function, equation (4), we have the best response function of the retail prices:

$$
\left\{\begin{array}{l}
P_{12}^{*}=\frac{(1-\varphi)\left(\alpha a_{1}+\gamma a_{2}\right)}{2\left(\alpha^{2}-\gamma^{2}\right)}+\frac{W_{1}}{2}+\frac{\alpha \beta_{1} P_{11}+\gamma \beta_{2} P_{21}}{2\left(\alpha^{2}-\gamma^{2}\right)}, \\
P_{22}^{*}=\frac{(1-\varphi)\left(\gamma a_{1}+\alpha a_{2}\right)}{2\left(\alpha^{2}-\gamma^{2}\right)}+\frac{W_{2}}{2}+\frac{\gamma \beta_{1} P_{11}+\alpha \beta_{2} P_{21}}{2\left(\alpha^{2}-\gamma^{2}\right)} .
\end{array}\right.
$$

From Proposition 2, we can conclude some properties of the retailer's response function, which appear in Corollary 1.

Corollary 1. For $i, j=1,2$, and $i \neq j$, we have

(a) $\left(\partial P_{i 2}^{*} / \partial W_{i}\right)=(1 / 2)>\left(\partial P_{i 2}^{*} / \partial W_{j}\right)=0$;

(b) $\left(\partial P_{12}^{*} / \partial P_{11}\right)=\left(\alpha \beta_{1} /\left(2\left(\alpha^{2}-\gamma^{2}\right)\right)\right)>\left(\partial P_{22}^{*} / \partial P_{11}\right)=$ $\left(\gamma \beta_{1} /\left(2\left(\alpha^{2}-\gamma^{2}\right)\right)\right)>0$ and $\left(\partial P_{22}^{*} / \partial P_{21}\right)=\left(\alpha \beta_{2} /\left(2\left(\alpha^{2}-\right.\right.\right.$ $\left.\left.\left.\gamma^{2}\right)\right)\right)>\left(\partial P_{12}^{*} / \partial P_{21}\right)=\left(\gamma \beta_{2} /\left(2\left(\alpha^{2}-\gamma^{2}\right)\right)\right)>0$.

Corollary 1 (a) indicates that the impact of $W_{1}$ on $P_{12}^{*}$ is the same as the impact of $W_{2}$ on $P_{22}^{*}$, and both impacts are equal to $(1 / 2)$, which implies that each product's wholesale price has the same impact on its retail price but has no effect on another product's retail price. The retail price of each product is directly affected by its wholesale price. However, no cross-effect exists between one product's wholesale price and another product's retail price since the two manufacturers make their wholesale prices independently.

Corollary 1 (b) reveals that retail price $P_{i 2}^{*}$ increases with direct prices $P_{11}$ and $P_{21}$. This statement seems inconsistent with our previous assumption, i.e., one product's direct price 
has no direct effect on another product's retail demand. However, this result is reasonable, considering that one product's direct price can indirectly affect the retail price of another product by influencing its direct price. Furthermore, one product's direct price has more of an effect on its retail price than on another product's retail price.

Obtaining the retailer's best response function, equation (8), the two manufacturers will determine their direct and wholesale prices simultaneously.

Proposition 3. The two manufacturers' optimal pricing strategies can be formulated as

$$
\left(P_{11}^{\mathrm{MS} *}, W_{1}^{\mathrm{MS} *}, P_{21}^{\mathrm{MS} *}, W_{2}^{\mathrm{MS} *}\right)^{T}=-A_{2}^{-1} B_{2},
$$

where $A_{2}$ and $B_{2}$ are shown in Appendix $A$.

Substituting equation (9) into equation (8), we can obtain the retailer's optimal pricing decisions $\left(P_{12}^{\mathrm{MS} *}, P_{22}^{\mathrm{MS} *}\right)$ for the MS model.

4.3. $M_{1}$ Leader Stackelberg Model. The market also consists of some manufacturers who usually occupy the leadership position when competing with other manufacturers or retailers. We call this kind of supply chain structure the $M_{1}$ leader Stackelberg model, that is, the $\mathrm{M}_{1} \mathrm{~S}$ model, in which $M_{1}$ is a leader in the supply chain and both $M_{2}$ and $R$ are followers. The decision sequences are as follows. First, $M_{1}$ decides its direct price $P_{11}$ and its wholesale price $W_{1}$. Then, $M_{2}$ determines its direct price $P_{21}$ and wholesale price $W_{2}$. Finally, the retailer selects its retail prices $P_{12}$ and $P_{22}$. The $\mathrm{M}_{1} \mathrm{~S}$ model is formulated as

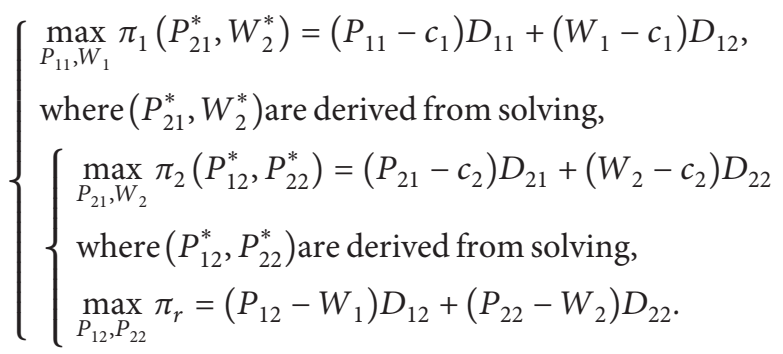

Similar to the MS model, we can obtain the optimal response functions of the retail prices (i.e., equation (8)). Now, we consider the response function of $M_{2}$ 's optimal decisions.

Proposition 4. With the retailer's optimal response functions, the optimal response functions for $M_{2}$ can be formulated:

$$
\left\{\begin{array}{l}
P_{21}^{*}=\frac{2 \alpha H_{3}+2 \alpha H_{1} P_{11}+\left(2 H_{4}+\gamma W_{1}\right) \beta_{2}}{-2\left(\alpha H_{2}+\beta_{2}^{2}\right)}, \\
W_{2}^{*}=\frac{H_{2}\left(2 H_{4}+\gamma W_{1}\right)-2\left(H_{3}+H_{1} P_{11}\right) \beta_{2}}{2\left(\alpha H_{2}+\beta_{2}^{2}\right)},
\end{array}\right.
$$

where $H_{k}$, for $k=1, \ldots, 4$ are shown in Appendix $A$.
From Proposition 4, we can examine how the decisions of the leader manufacturer (i.e., $M_{1}$ ) affect the optimal strategies of the follower manufacturer (i.e., $M_{2}$ ). The results are shown in Corollary 2.

Corollary 2. The effect of $M_{1}$ 's decision on $M_{2}$ 's optimal strategies

$$
\begin{aligned}
& \text { (a) }\left(\partial P_{21}^{*} / \partial W_{1}\right)>0, \quad\left(\partial P_{21}^{*} / \partial P_{11}\right)>0, \quad\left(\partial W_{2}^{*} / \partial W_{1}\right)>0 \text {, } \\
& \text { and }\left(\partial W_{2}^{*} / \partial P_{11}\right)>0 \\
& \text { (b) }\left(\partial W_{2}^{*} / \partial P_{11}\right)<\left(\partial P_{21}^{*} / \partial P_{11}\right) \quad \text { and } \\
& \left(\partial W_{2}^{*} / \partial W_{1}\right)>\left(\partial P_{21}^{*} / \partial W_{1}\right) .
\end{aligned}
$$

Corollary 2 (a) indicates that both the optimal direct and wholesale prices of $M_{2}$ increase with each price decision of $M_{1}$, including the direct or wholesale price. When $M_{1}$ raises its price, $M_{2}$ has to increase its price to compete with $M_{1}$. This conclusion is rational because $M_{1}$ is the leader in the $\mathrm{M}_{1} \mathrm{~S}$ model; hence, $M_{2}$ will follow $M_{1}$ and adjust its optimal pricing decisions accordingly.

Corollary 2 (b) shows that the impact of $M_{1}$ 's direct price $P_{11}$ on $M_{2}$ 's optimal wholesale price $W_{2}^{*}$ is lower than the impact of $M_{1}$ 's direct price $P_{11}$ on $M_{2}$ 's optimal direct price $P_{21}^{*}$, while the effect of $M_{1}$ 's wholesale price $W_{1}$ on $M_{2}$ 's optimal wholesale price $W_{2}^{*}$ is higher than the effect of $M_{1}$ 's wholesale price $W_{1}$ on $M_{2}$ 's optimal direct price $P_{21}^{*}$. These results show that in the $\mathrm{M}_{1} \mathrm{~S}$ model, $M_{2}$ 's optimal price strategies are mainly influenced by the corresponding prices of $M_{1}$.

Anticipating the optimal response functions of $R$ and $M_{2}$, we can obtain $M_{1}$ 's optimal price decisions.

Proposition 5. With the optimal response functions of $R$ and $M_{2}$, the optimal pricing strategies for $M_{1}$ can be formulated as

$$
\left\{\begin{array}{l}
P_{11}^{M_{1} S *}=\frac{K_{3} K_{4}-K_{2} K_{5}}{K_{2}^{2}-K_{1} K_{4}}, \\
W_{1}^{M_{1} S *}=\frac{K_{1} K_{5}-K_{2} K_{3}}{K_{2}^{2}-K_{1} K_{4}},
\end{array}\right.
$$

where $K_{l}$, for $l=1, \ldots, 5$ are shown in Appendix A.

Substituting equation (12) into equation (11), we can obtain the optimal price strategies of $M_{2}$. Substituting equations (11) and (12) into equation (8), we can acquire the optimal pricing decisions of $M_{1}$. Therefore, we have equilibrium results in the $\mathrm{M}_{1} \mathrm{~S}$ model.

\section{Numerical Simulations}

To intuitively show the implication of channel discrepancy on the equilibrium results and profits and to verify these conclusions by using the numerical analysis method, we proceed with the numerical simulations in this section. The method of numerical analysis has been widely adopted by many works of the literature in dual-channel supply chain management $[2,4,8,9]$. For example, Lu et al. [4] believe that using numerical analytical methods to explore the 
management insights of parameters under different market power structures is appropriate. Therefore, we examine the numerical simulations to investigate the effect of $M_{1}$ 's channel discrepancy on the optimal prices, demands, and profits in three different market power structures.

In the literature, the impact of cross-product effect $\gamma$ on the equilibrium results has been explored by Choi [7] in detail. Jena and Sarmah [10] examine the impacts of selfprice effect $\alpha$ and market size $a$ on the equilibrium results. The impact of $\beta_{2}$ on the equilibrium results is similar to that of $\beta_{1}$ because the model is symmetrical. Therefore, we concentrate our attention only on the effect of $\beta_{1}$ on the optimal strategies and profits, which is also consistent with the main research motivations of this article. We deliberate on how the prices, demands, and profits vary when channel discrepancy is as a higher level, and we offer some explanations for the results. Referring to the existing literature $[6,7]$ and following the assumptions for the parameters in this study, we set $\beta_{1}$ as varying from 2 to 5 and let the other parameters be $a_{1}=a_{2}=400, \alpha=11, \beta_{2}=3, \gamma=4, \varphi=0.5$, and $c_{1}=c_{2}=10$ to make the model feasible and meaningful. Note that in this parameter setting, $\alpha$ is obviously greater than $\beta_{i}$ and $\gamma$, while $\beta_{i}$ and $\gamma$ are relatively close. This is also consistent with our construction logic for equation (1), where the self-price effect is the primary factor affecting demand, while the cross-channel and cross-product effects are both secondary factors.

Figure 2 gives the impact of $M_{1}$ 's channel discrepancy on the profits of the retailer, manufacturer, and supply chain. As seen from Figures 2(a) and 2(b), the profits of either the retailer or the manufacturer increase in $\beta_{1}$. This result demonstrates that a higher level of channel discrepancy for $M_{1}$ will improve not only $M_{1}$ 's profit but also those of $R$ and $M_{2}$. The increasing speed of $M_{1}$ 's profit to $\beta_{1}$ is higher than that for $M_{2}$, which means that $M_{1}$ can earn more profit than $M_{2}$ when facing a higher level of channel discrepancy. Additionally, each manufacturer's profit is always lower in the MS model than it is in the $\mathrm{M}_{1} \mathrm{~S}$ model, while it is always higher in the MS model than it is in the N model. However, the results for the retailer are exactly the opposite. The retailer's profit in the MS model is higher than that in the $\mathrm{M}_{1} \mathrm{~S}$ model but lower than that in the $\mathrm{N}$ model. Figure 2(c) indicates that the profit of the supply chain increases with $M_{1}$ 's channel discrepancy, which means that a higher level of channel discrepancy for $M_{1}$ benefits the whole system. Additionally, the profit in the $\mathrm{M}_{1} \mathrm{~S}$ model is lower than that in the $\mathrm{N}$ model when $\beta_{1}$ is relatively small and it exceeds the profit in the $\mathrm{N}$ model when $\beta_{1}$ increases to a certain threshold. From Figure 2(c), we find that the profit in the MS model is always lower than it is in the $\mathrm{M}_{1} \mathrm{~S}$ and $\mathrm{N}$ models.

As shown in Figure 3(a), each direct price increases in $M_{1}$ 's channel discrepancy, and the impact of $\beta_{1}$ on product l's direct price is higher than that on product 2's direct price in all three models. When we compare the equilibrium price strategies in the three models, we find that Figure 3(a) shows that the direct price of the $M_{1}$ is significantly higher in the $M_{1} S$ model than it is in the other two models, while the direct price of $M_{1}$ is always lower in the $\mathrm{N}$ model than it is in the MS and $\mathrm{M}_{1} \mathrm{~S}$ models. This result is evident because, in the $\mathrm{N}$ model, the manufacturer, lacking the leader advantage, can compete with the retailer only by lowering its direct price. Figure 3(b) indicates that the retail prices for the two products increase in $\beta_{1}$, and the effect of $\beta_{1}$ on product 1's retail price is higher than it is on product 2's retail price, regardless of whether the result is derived from the $\mathrm{M}_{1} \mathrm{~S}$, the MS, or the $\mathrm{N}$ model. These results are similar to those found in the direct channel. However, in the different models, the change in the retail price is different from that in the direct price. Specifically, regardless of whether a manufacturer dominates over the retailer, the manufacturer will exert a significant impact on the retail price.

Figure 4(a) indicates that the demand for each direct channel increases in $\beta_{1}$ in the three models. Further analysis is now provided. From Figure 3(a), we know that the direct price increases in $\beta_{1}$, which may induce the direct demand to decrease in $\beta_{1}$ due to the self-price effect. Taking the direct demand of product 1 as an example, i.e., $D_{11}$, Figure 3(a) shows that $P_{11}$ increases in $\beta_{1}$ and equation (1) shows that $D_{11}$ decreases in $P_{11}$, both of which induce $D_{11}$ to decrease in $\beta_{1}$. However, we can also find from Figure 3(a) that both $P_{12}$ and $P_{21}$ increase in $\beta_{1}$, which induces $D_{11}$ to increase in $\beta_{1}$. Therefore, $D_{11}$ increases in $\beta_{1}$. Additionally, Figure 4(a) suggests that, for the leader manufacturer, its direct demand in the $\mathrm{N}$ model is higher than that in the $\mathrm{M}_{1} \mathrm{~S}$ model and lower than that in the MS model, while for the follower manufacturer, its direct demand in the MS model is higher than that in the $\mathrm{N}$ model and lower than that in the $\mathrm{M}_{1} \mathrm{~S}$ model. Figure 4(b) indicates that each retail demand increases in $\beta_{1}$, whose trend is similar to the curves of the direct demands in Figure 4(a). However, the differences in retail demands among different models are distinct from those in direct demands. On the one hand, the retail demand in the $\mathrm{N}$ model is always higher than it is in the other models. On the other hand, the retail demand on product 1 in the $\mathrm{M}_{1} \mathrm{~S}$ model is lower than the other models, while the retail demand on product 2 in the $\mathrm{M}_{1} \mathrm{~S}$ model is somewhere between its value as found in the MS and N models.

\section{Managerial Insights}

In this section, we discuss the managerial insights of this study. In the situation of a dual-channel supply chain, the manufacturer and the retailer compete with each other in the market. Therefore, the dual-channel supply chain members must obtain an overall understanding of the implication of channel discrepancy on the optimal strategies and profits under different market power structures and accordingly improve the effectiveness of their dual-channel operations. Two main managerial insights are derived from this work and presented as follows.

From the numerical simulations, we find that all retail and direct prices increase along with the level of channel discrepancy. This finding implies that a higher level of channel discrepancy between the retail and direct channels induces both the manufacturer and the retailer to increase their sales prices. From the customer's point of view, however, a higher level of channel discrepancy may result in a lower manufacturer's reputation. Therefore, managers should make a trade-off between a higher channel 


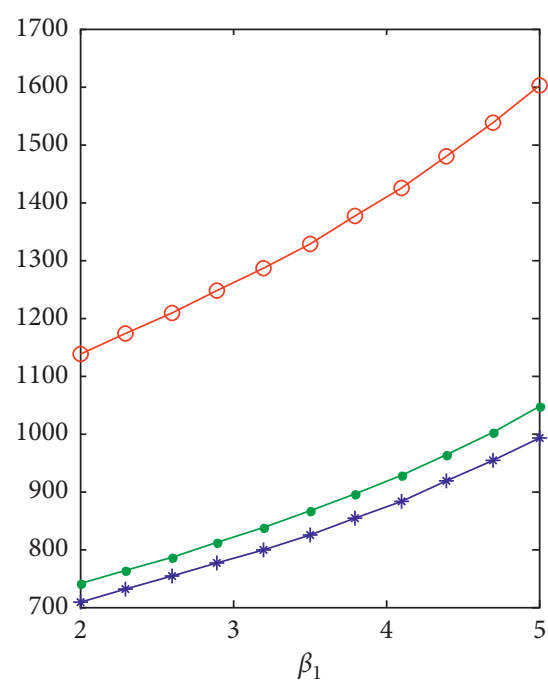

$$
\begin{aligned}
& \rightarrow \pi_{\mathrm{r} 1}^{\mathrm{M}_{1} \mathrm{~S}} \\
& \multimap \pi_{\mathrm{r}}^{\mathrm{MS}} \\
& \multimap \pi_{\mathrm{r}}^{\mathrm{N}}
\end{aligned}
$$

(a)

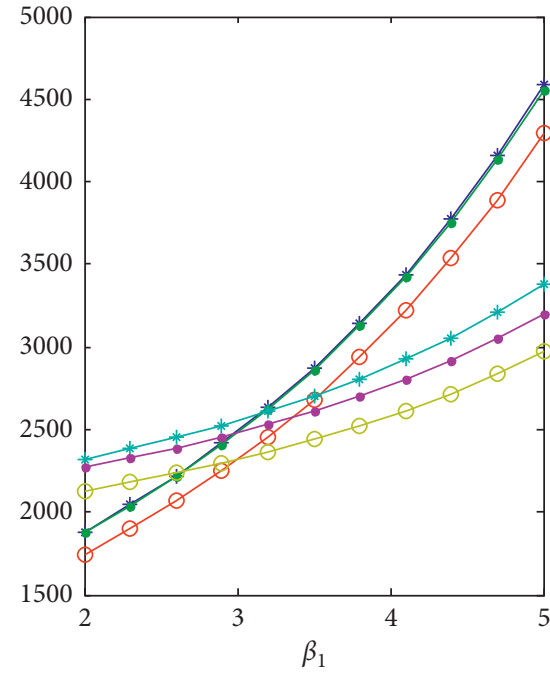

$$
\begin{aligned}
& \rightarrow \pi_{1}^{\mathrm{M}_{1} \mathrm{~S}} \quad \rightarrow * \pi_{2}^{\mathrm{M}_{1} \mathrm{~S}} \\
& \because \pi_{2}^{\mathrm{MS}} \\
& \rightarrow \pi_{1}^{\mathrm{MS}} \\
& \curvearrowleft \pi_{2}^{\mathrm{N}}
\end{aligned}
$$

(b)

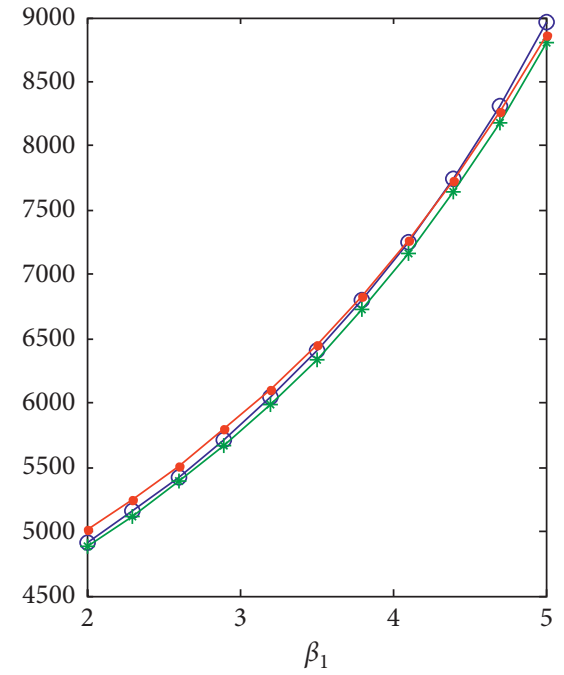

$$
\begin{aligned}
& \multimap \pi^{\mathrm{M}_{1} \mathrm{~S}} \\
& \rightarrow-\pi^{\mathrm{MS}} \\
& \rightarrow-\pi^{\mathrm{N}}
\end{aligned}
$$

(c)

Figure 2: The effect of $\beta_{1}$ on the optimal profits in three models: (a) retailer profit; (b) manufacturer profit; (c) total profit.

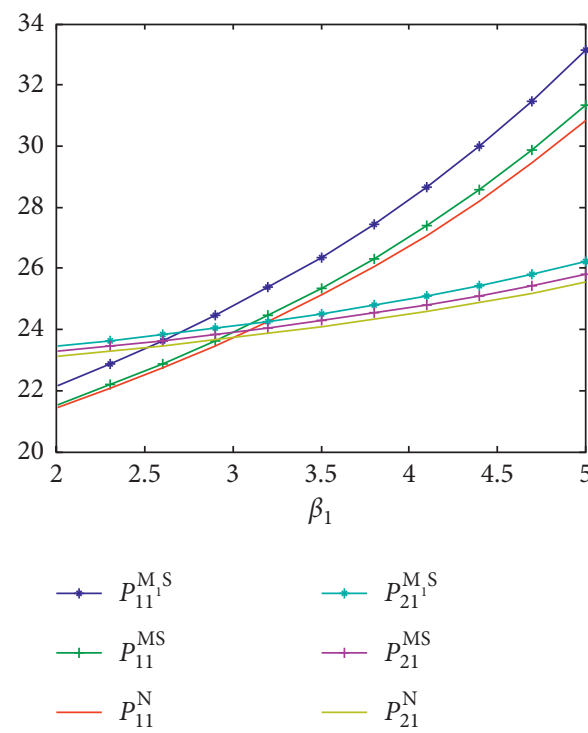

(a)

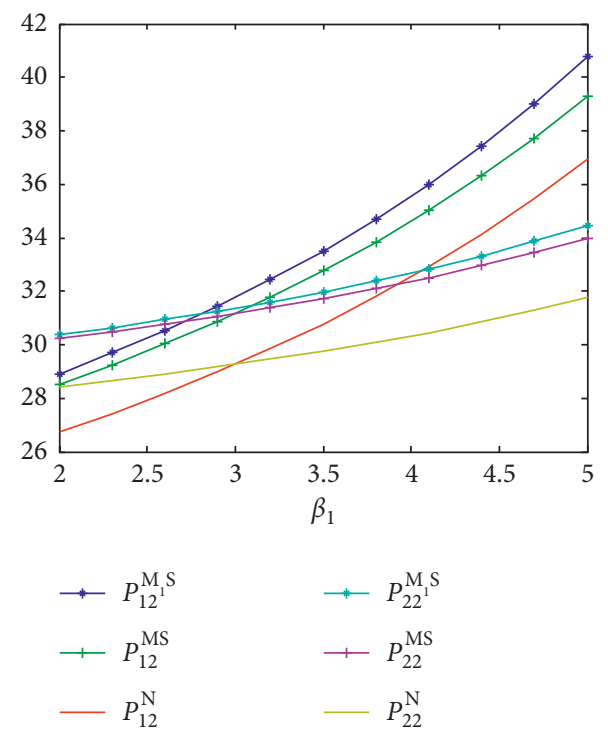

(b)

FIgURE 3: The effect of $\beta_{1}$ on the optimal prices in the three models: (a) direct price; (b) retail price.

discrepancy which can create a higher marginal profit and a lower channel discrepancy which benefits consumers through providing a lower sales price. Moreover, any sales price in the MS model is always higher than that in the $\mathrm{N}$ model but lower than that in the $\mathrm{M}_{1} \mathrm{~S}$ model. This result means that the market power difference among channel members always leads to a higher sales price.
Comparing the optimal profits of the supply chain among three market power structures, we find that the profit in the $\mathrm{N}$ model is always higher than that in the MS model, while it may be higher or lower than that in the $M_{1} S$ model depending on $M_{1}$ 's channel discrepancy. When the retailer is a follower in the Stackelberg game, the profit of the supply chain in which manufacturers have the same market power 


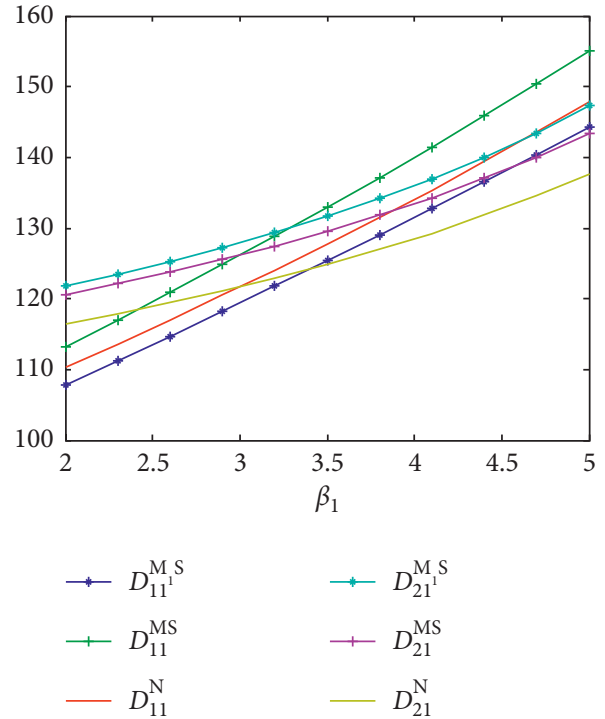

(a)
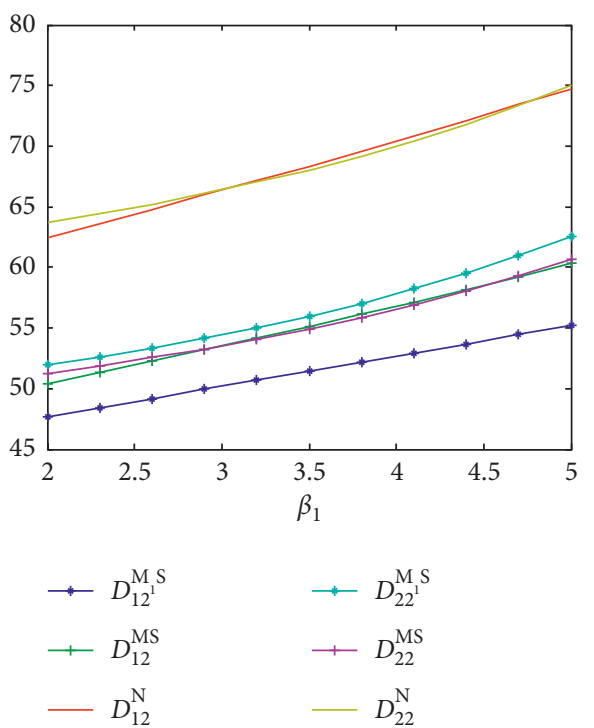

(b)

Figure 4: The effect of $\beta_{1}$ on the optimal demands in the three models: (a) direct demand; (b) retail demand.

is lower than that in the Nash game. When manufacturers have different market powers, however, the leader manufacturer with a higher level of channel discrepancy can alleviate or even resolve this phenomenon. Therefore, when two manufacturers engage in the Stackelberg game, the leader manufacturer should make efforts to improve its channel discrepancy.

\section{Conclusions}

This study provides a direction for the research of dualchannel supply chains in the presence of channel product competition. We propose a mathematical model consisting of two manufacturers and one common retailer to explore the implications of channel discrepancy on optimal prices, demands, and profits in three different market power structures, which are described as the $\mathrm{M}_{1} \mathrm{~S}$, MS, $\mathrm{N}$ models. In this theoretical model, both manufacturers open their direct channels to sell substitutable products to their customers. We derive the optimal pricing strategies and examine the properties associated with these strategies. The numerical simulations are also examined to explore and verify the effects of $M_{1}$ 's channel discrepancy on the optimal strategies.
We find that as $M_{1}$ 's channel discrepancy increases, all equilibrium results-including prices, demands, and profits - in both the direct and retail channels increase as well. The impact of $M_{1}$ 's channel discrepancy on $M_{1}$ is larger than that on $M_{2}$. From the product point of view, a higher level of $M_{1}$ 's channel discrepancy induces the optimal prices, demands, and profits of $M_{1}$ to increase rapidly and to soon exceed those of $M_{2}$. More interestingly, comparing the optimal profit in the three models, we find that the profit in the $\mathrm{N}$ model is always higher than that in the MS model and may be higher or lower than that in the $\mathrm{M}_{1} \mathrm{~S}$ model, depending on the level of $M_{1}$ 's channel discrepancy.

In this study, we consider a simple situation of a dualchannel supply chain, in which the pricing strategies are the only consideration in the different market power structures. Future studies can focus on other strategies such as retail service, lead time, and product quality to explore the implication of channel discrepancy. Furthermore, the model in this study is based on the linear demand function under a deterministic environment. We believe that developing nonlinear models under an uncertain environment will be an interesting research direction. 


\section{Appendix}

\section{Appendix A}

$$
\begin{aligned}
A_{1} & =\left(\begin{array}{cccccc}
-2 \alpha & \beta_{1} & \gamma & 0 & \beta_{1} & 0 \\
2 \beta_{1} & -\alpha & 0 & 0 & -\alpha & \gamma \\
\gamma & 0 & -2 \alpha & \beta_{2} & 0 & \beta_{2} \\
0 & 0 & 2 \beta_{2} & -\alpha & \gamma & -\alpha \\
\beta_{1} & \alpha & 0 & -\gamma & -2 \alpha & 2 \gamma \\
0 & -\gamma & \beta_{2} & \alpha & 2 \gamma & -2 \alpha
\end{array}\right), \\
B_{1} & =\left(\begin{array}{c}
\varphi a_{1}+c_{1}\left(\alpha-\beta_{1}\right) \\
(1-\varphi) a_{1}+c_{1}\left(\alpha-\beta_{1}\right) \\
\varphi a_{2}+c_{2}\left(\alpha-\beta_{2}\right) \\
(1-\varphi) a_{2}+c_{2}\left(\alpha-\beta_{2}\right) \\
(1-\varphi) a_{1} \\
(1-\varphi) a_{2}
\end{array}\right),
\end{aligned}
$$$$
A_{2}=\left(\begin{array}{cccc}
2 \alpha\left(\beta_{1}^{2}-2\left(\alpha^{2}-\gamma^{2}\right)\right) & 2\left(\alpha^{2}-\gamma^{2}\right) \beta_{1} & 2 \gamma\left(\alpha^{2}-\gamma^{2}\right)+\gamma \beta_{1} \beta_{2} & 0 \\
2 \beta_{1} & -2 \alpha & 0 & \gamma \\
\gamma\left(2\left(\alpha^{2}-\gamma^{2}\right)+\beta_{1} \beta_{2}\right) & 0 & 2 \alpha\left(\beta_{2}^{2}-2\left(\alpha^{2}-\gamma^{2}\right)\right) & 2\left(\alpha^{2}-\gamma^{2}\right) \beta_{2} \\
0 & \gamma & 2 \beta_{2} & -2 \alpha
\end{array}\right),
$$$$
B_{2}=\left(\begin{array}{c}
\gamma(1-\varphi) a_{2} \beta_{1}+a_{1}\left(2\left(\alpha^{2}-\gamma^{2}\right) \varphi+\alpha(1-\varphi) \beta_{1}\right)+c_{1}\left(\left(\alpha^{2}-\gamma^{2}\right)\left(2 \alpha-\beta_{1}\right)-\alpha \beta_{1}^{2}\right) \\
(1-\varphi) a_{1}+c_{1}\left(\alpha-\beta_{1}\right) \\
\gamma(1-\varphi) a_{1} \beta_{2}+a_{2}\left(2\left(\alpha^{2}-\gamma^{2}\right) \varphi+\alpha(1-\varphi) \beta_{2}\right)+c_{2}\left(\left(\alpha^{2}-\gamma^{2}\right)\left(2 \alpha-\beta_{2}\right)-\alpha \beta_{2}^{2}\right) \\
(1-\varphi) a_{2}+c_{2}\left(\alpha-\beta_{2}\right)
\end{array}\right) \text {, }
$$$$
H_{1}=\gamma+\frac{\beta_{1} \beta_{2} \gamma}{2\left(\alpha^{2}-\gamma^{2}\right)}
$$$$
H_{2}=\frac{\alpha \beta_{2}^{2}}{\alpha^{2}-\gamma^{2}}-2 \alpha,
$$$$
H_{3}=\frac{\gamma(1-\varphi) a_{1} \beta_{2}+a_{2}\left(2\left(\alpha^{2}-\gamma^{2}\right) \varphi+\alpha(1-\varphi) \beta_{2}\right)+c_{2}\left(\left(\alpha^{2}-\gamma^{2}\right)\left(2 \alpha-\beta_{2}\right)-\alpha \beta_{2}^{2}\right)}{2\left(\alpha^{2}-\gamma^{2}\right)},
$$

$H_{4}=\frac{1}{2}\left((1-\varphi) a_{2}+c_{2}\left(\alpha-\beta_{2}\right)\right)$,

$K_{1}=\frac{\alpha \beta_{1}^{2}}{\alpha^{2}-\gamma^{2}}-2 \alpha-\frac{2 \alpha \gamma H_{1}}{\alpha H_{2}+\beta_{2}^{2}}-\frac{\alpha \gamma H_{1} \beta_{1} \beta_{2}}{\left(\alpha^{2}-\gamma^{2}\right)\left(\alpha H_{2}+\beta_{2}^{2}\right)}$,

$K_{2}=\frac{\left(4 \alpha\left(\alpha^{2}-\gamma^{2}\right) H_{2} \beta_{1}+\beta_{2}\left(2 \gamma\left(-\alpha^{2}+\gamma^{2}\right)\left(\gamma+H_{1}\right)+\left(4 \alpha^{2}-5 \gamma^{2}\right) \beta_{1} \beta_{2}\right)\right)}{4\left(\alpha^{2}-\gamma^{2}\right)\left(\alpha H_{2}+\beta_{2}^{2}\right)}$,

$K_{3}=\frac{K_{31}+c_{1} K_{32}}{2\left(\alpha^{2}-\gamma^{2}\right)\left(\alpha H_{2}+\beta_{2}^{2}\right)}$,

$K_{4}=\frac{1}{2}\left(\frac{\gamma^{2} H_{2}}{\alpha H_{2}+\beta_{2}^{2}}-2 \alpha\right)$,

$K_{5}=\frac{K_{51}+c_{1} K_{52}}{4\left(\alpha^{2}-\gamma^{2}\right)\left(\alpha H_{2}+\beta_{2}^{2}\right)}$,

$K_{31}=\left(\gamma(1-\varphi) a_{2} \beta_{1}+a_{1}\left(2\left(\alpha^{2}-\gamma^{2}\right) \varphi+\alpha(1-\varphi) \beta_{1}\right)\right)\left(\alpha H_{2}+\beta_{2}^{2}\right)-\gamma\left(\alpha H_{3}+H_{4} \beta_{2}\right)\left(2 \alpha^{2}-2 \gamma^{2}+\beta_{1} \beta_{2}\right)$.

$K_{32}=\left(\left(\alpha^{2}-\gamma^{2}\right)\left(2 \alpha-\beta_{1}\right)-\alpha \beta_{1}^{2}\right)\left(\alpha H_{2}+\beta_{2}^{2}\right)+\gamma H_{1}\left(\alpha \beta_{1} \beta_{2}+\left(\alpha^{2}-\gamma^{2}\right)\left(2 \alpha+\beta_{2}\right)\right)$,

$K_{51}=2\left(\alpha^{2}-\gamma^{2}\right)\left(\gamma\left(H_{2} H_{4}-H_{3} \beta_{2}\right)+(1-\varphi) a_{1}\left(\alpha H_{2}+\beta_{2}^{2}\right)\right)$,

$K_{52}=\left(\alpha^{2}-\gamma^{2}\right) H_{2}\left(2 \alpha^{2}-\gamma^{2}-2 \alpha \beta_{1}\right)+\beta_{2}\left(2 \gamma^{2}\left(\alpha^{2}-\gamma^{2}\right)+\left(2 \alpha^{3}-2 \alpha \gamma^{2}-2 \alpha^{2} \beta_{1}+3 \gamma^{2} \beta_{1}\right) \beta_{2}\right)$. 


\section{Appendix B}

Proof of Proposition 1. Letting $P_{i 2}=m_{i}+W_{i}$, for $i=1$, 2, we have

$$
\begin{aligned}
& \nabla^{2} \pi_{1}\left(P_{11}, W_{1}\right)=\left(\begin{array}{cc}
-2 \alpha & \beta_{1} \\
2 \beta_{1} & -\alpha
\end{array}\right), \\
& \nabla^{2} \pi_{2}\left(P_{21}, W_{2}\right)=\left(\begin{array}{cc}
-2 \alpha & \beta_{2} \\
2 \beta_{2} & -\alpha
\end{array}\right), \\
& \nabla^{2} \pi_{r}\left(P_{12}, P_{22}\right)=\left(\begin{array}{cc}
-2 \alpha & 2 \gamma \\
2 \gamma & -2 \alpha
\end{array}\right) .
\end{aligned}
$$

From Assumption 2, we know that these Hessian matrices are negative definite. Hence, from the first-order conditions, i.e., $A_{1}\left(P_{11}, W_{1}, P_{21}, W_{2}, P_{12}, P_{22}\right)^{T}+B_{1}=0$, we have $\left(P_{11}^{N *}, W_{1}^{N *}, P_{21}^{N *}, W_{2}^{N *}, P_{12}^{N *}, P_{22}^{N *}\right)^{T}=-A_{1}^{-1} B_{1}$.

Proof of Proposition 2. From the Proof of Proposition 1, we know that the Hessian matrix of $\nabla^{2} \pi_{r}\left(P_{12}, P_{22}\right)$ is negative definite. Therefore, we can get the retailer's response functions by solving equations $\left(\partial \pi_{3} / \partial P_{12}\right)=0$ and $\left(\partial \pi_{3} / \partial P_{22}\right)=0$

Proof of Proposition 3. After having the retailer's response functions, we have

$$
\begin{aligned}
& \nabla^{2} \pi_{1}\left(P_{11}, W_{1}\right)=\left(\begin{array}{cc}
-2 \alpha+\frac{\alpha \beta_{1}^{2}}{\alpha^{2}-\gamma^{2}} & \beta_{1} \\
\beta_{1} & -\alpha
\end{array}\right), \\
& \nabla^{2} \pi_{2}\left(P_{21}, W_{2}\right)=\left(\begin{array}{cc}
-2 \alpha+\frac{\alpha \beta_{2}^{2}}{\alpha^{2}-\gamma^{2}} & \beta_{2} \\
\beta_{2} & -\alpha
\end{array}\right) .
\end{aligned}
$$

From Assumption 2, these Hessian matrices are negative definite. Therefore, from the first-order conditions, we have $A_{2}\left(P_{11}, W_{1}, P_{21}, W_{2}\right)^{T}+B_{2}=0$.

Therefore, $\left(P_{11}^{\mathrm{MS} *}, W_{1}^{\mathrm{MS} *}, P_{21}^{\mathrm{MS} *}, W_{2}^{\mathrm{MS} *}\right)^{T}=-A_{2}^{-1} B_{2}$.

Proof of Proposition 4. Having the retailer's response function, for $M_{2}$, we have

$$
\begin{gathered}
\frac{\partial \pi_{2}}{\partial P_{21}}=H_{3}+H_{1} P_{11}+H_{2} P_{21}+W_{2} \beta_{2}, \\
\frac{\partial \pi_{2}}{\partial W_{2}}=H_{4}+\frac{\gamma W_{1}}{2}-\alpha W_{2}+P_{21} \beta_{2},
\end{gathered}
$$

where $H_{k}$ (for $\left.k=1, \ldots, 4\right)$ are shown in Appendix A.

From Assumption 2, $H_{2}<0$ and $\alpha H_{2}+\beta_{2}^{2}<0$; thus, $\pi_{2}$ is joint concave with $P_{21}$ and $W_{2}$. Solving $\left(\partial \pi_{2} / \partial P_{21}\right)=0$ and $\left(\partial \pi_{2} / \partial W_{2}\right)=0$, we have equation (7).

Proof of Proposition 5. After obtaining the retailer's and $M_{2}$ 's response functions, for $M_{1}$, we have

$$
\begin{aligned}
& \frac{\partial \pi_{1}}{\partial P_{11}}=K_{3}+K_{1} P_{11}+K_{2} W_{1}, \\
& \frac{\partial \pi_{1}}{\partial W_{1}}=K_{5}+K_{2} P_{11}+K_{4} W_{1},
\end{aligned}
$$

where $K_{l}$ (for $\left.l=1, \ldots, 5\right)$ are shown in Appendix A. Therefore, we have $\nabla^{2} \pi_{1}\left(P_{11}, W_{1}\right)=\left(\begin{array}{ll}K_{1} & K_{2} \\ K_{2} & K_{4}\end{array}\right)$. It is easy to prove $K_{1}<0$ and $K_{4}<0$. Considering Assumption 3 (i.e., $K_{2}^{2}-K_{1} K_{4}<0$ ), we know that $\pi_{1}$ is jointly concave with $P_{11}$ and $W_{1}$ since the Hessian matrices are negative definite. Solving equations $\left(\partial \pi_{1} / \partial P_{11}\right)=0$ and $\left(\partial \pi_{1} / \partial W_{1}\right)=0$, we can get equation (8).

Proof of Corollary 2

$$
\begin{aligned}
& \text { (a) } \frac{\partial P_{21}^{*}}{\partial W_{1}}=\frac{\gamma\left(\alpha^{2}-\gamma^{2}\right) \beta_{2}}{2\left(2 \alpha^{2}\left(\alpha^{2}-\gamma^{2}-\beta_{2}^{2}\right)+\gamma^{2} \beta_{2}^{2}\right)}>0, \\
& \frac{\partial P_{21}^{*}}{\partial P_{11}}=\frac{\alpha \gamma\left(2 \alpha^{2}-2 \gamma^{2}+\beta_{1} \beta_{2}\right)}{2\left(2 \alpha^{2}\left(\alpha^{2}-\gamma^{2}-\beta_{2}^{2}\right)+\gamma^{2} \beta_{2}^{2}\right)}>0, \\
& \frac{\partial W_{2}^{*}}{\partial W_{1}}=\frac{\alpha \gamma\left(2 \alpha^{2}-2 \gamma^{2}-\beta_{2}^{2}\right)}{2\left(2 \alpha^{2}\left(\alpha^{2}-\gamma^{2}-\beta_{2}^{2}\right)+\gamma^{2} \beta_{2}^{2}\right)}>0, \\
& \frac{\partial W_{2}^{*}}{\partial P_{11}}=\frac{\gamma \beta_{2}\left(2 \alpha^{2}-2 \gamma^{2}+\beta_{1} \beta_{2}\right)}{2\left(2 \alpha^{2}\left(\alpha^{2}-\gamma^{2}-\beta_{2}^{2}\right)+\gamma^{2} \beta_{2}^{2}\right)}>0, \\
& \text { (b) } \frac{\partial W_{2}^{*}}{\partial P_{11}}-\frac{\partial P_{21}^{*}}{\partial P_{11}}=-\frac{\gamma\left(\alpha-\beta_{2}\right)\left(2 \alpha^{2}-2 \gamma^{2}+\beta_{1} \beta_{2}\right)}{2\left(2 \alpha^{2}\left(\alpha^{2}-\gamma^{2}-\beta_{2}^{2}\right)+\gamma^{2} \beta_{2}^{2}\right)}<0, \\
& \frac{\partial W_{2}^{*}}{\partial W_{1}}-\frac{\partial P_{21}^{*}}{\partial W_{1}}=\frac{\gamma\left(\alpha^{2}-\gamma^{2}\right)\left(\alpha-\beta_{2}\right)+\alpha \gamma\left(\alpha^{2}-\gamma^{2}-\beta_{2}^{2}\right)}{2\left(2 \alpha^{2}\left(\alpha^{2}-\gamma^{2}-\beta_{2}^{2}\right)+\gamma^{2} \beta_{2}^{2}\right)}>0 .
\end{aligned}
$$

\section{Data Availability}

The data used to support the findings of this study are included within the article.

\section{Conflicts of Interest}

The authors declare that they have no conflicts of interest.

\section{Authors' Contributions}

All authors contributed equally to this work.

\section{Acknowledgments}

The authors acknowledge the support from the National Natural Science Foundation of China, Project 71642001. 


\section{References}

[1] W.-Y. K. Chiang, D. Chhajed, and J. D. Hess, "Direct marketing, indirect profits: a strategic analysis of dual-channel supply-chain design," Management Science, vol. 49, no. 1, pp. 1-20, 2003.

[2] Z. Pi, W. Fang, and B. Zhang, "Service and pricing strategies with competition and cooperation in a dual-channel supply chain with demand disruption," Computers \& Industrial Engineering, vol. 138, p. 106130, 2019.

[3] R. Batarfi, M. Y. Jaber, and S. Zanoni, "Dual-channel supply chain: a strategy to maximize profit," Applied Mathematical Modelling, vol. 40, no. 21-22, pp. 9454-9473, 2016.

[4] J.-C. Lu, Y.-C. Tsao, and C. Charoensiriwath, "Competition under manufacturer service and retail price," Economic Modelling, vol. 28, no. 3, pp. 1256-1264, 2011.

[5] L. Ma, R. Zhang, S. Guo, and B. Liu, "Pricing decisions and strategies selection of dominant manufacturer in dualchannel supply chain," Economic Modelling, vol. 29, no. 6, pp. 2558-2565, 2012.

[6] J. Zhao, J. Wei, J. Wei, and Y. Li, "Pricing and remanufacturing decisions for two substitutable products with a common retailer," Journal of Industrial \& Management Optimization, vol. 13, no. 2, pp. 1125-1147, 2017.

[7] S. C. Choi, "Price competition in a channel structure with a common retailer," Marketing Science, vol. 10, no. 4, pp. 271-296, 1991.

[8] L. Wang, H. Song, and Y. Wang, "Pricing and service decisions of complementary products in a dual-channel supply chain," Computers \& Industrial Engineering, vol. 105, pp. 223-233, 2017.

[9] J. Wei, J. Zhao, and Y. Li, "Pricing decisions for complementary products with firms' different market powers," $E u$ ropean Journal of Operational Research, vol. 224, no. 3, pp. 507-519, 2013.

[10] S. K. Jena and S. P. Sarmah, "Price and service co-opetiton under uncertain demand and condition of used items in a remanufacturing system," International Journal of Production Economics, vol. 173, pp. 1-21, 2016.

[11] K. Cattani, W. Gilland, H. S. Heese, and J. Swaminathan, "Boiling frogs: pricing strategies for a manufacturer adding a direct channel that competes with the traditional channel," Production and Operations Management, vol. 15, no. 1, pp. 40-56, 2006.

[12] S. Y. Park and H. T. Keh, "Modelling hybrid distribution channels: a game-theoretic analysis," Journal of Retailing and Consumer Services, vol. 10, no. 3, pp. 155-167, 2003.

[13] W. Huang and J. M. Swaminathan, "Introduction of a second channel: implications for pricing and profits," European Journal of Operational Research, vol. 194, no. 1, pp. 258-279, 2009.

[14] G. Hua, S. Wang, and T. C. E. Cheng, "Price and lead time decisions in dual-channel supply chains," European Journal of Operational Research, vol. 205, no. 1, pp. 113-126, 2010.

[15] J. Q. Yang, X. M. Zhang, H. Y. Fu, and C. Liu, "Inventory competition in a dual-channel supply chain with delivery lead time consideration," Applied Mathematical Modelling, vol. 42, pp. 675-692, 2017.

[16] N. M. Modak and P. Kelle, "Managing a dual-channel supply chain under price and delivery-time dependent stochastic demand," European Journal of Operational Research, vol. 272, no. 1, pp. 147-161, 2019.
[17] B. Li, M. Zhu, Y. Jiang, and Z. Li, "Pricing policies of a competitive dual-channel green supply chain," Journal of Cleaner Production, vol. 112, pp. 2029-2042, 2016.

[18] J. Ji, Z. Zhang, and L. Yang, "Carbon emission reduction decisions in the retail-/dual-channel supply chain with consumer' preference," Journal of Cleaner Production, vol. 141, pp. 852-867, 2017.

[19] A. Ranjan and J. K. Jha, "Pricing and coordination strategies of a dual-channel supply chain considering green quality and sales effort," Journal of Cleaner Production, vol. 218, pp. 409-424, 2019.

[20] T. Xiao and D. Yang, "Price and service competition of supply chains with risk-averse retailers under demand uncertainty," International Journal of Production Economics, vol. 114, no. 1, pp. 187-200, 2008.

[21] Q. H. Li and B. Li, "Dual-channel supply chain equilibrium problems regarding retail services and fairness concerns," Applied Mathematical Modelling, vol. 40, no. 15-16, pp. 7349-7367, 2016.

[22] L. Liu, L. Feng, B. Xu, and W. Deng, "Operation strategies for an omni-channel supply chain: who is better off taking on the online channel and offline service?" Electronic Commerce Research and Applications, vol. 39, p. 100918, 2020.

[23] Y.-W. Zhou, J. Guo, and W. Zhou, "Pricing/service strategies for a dual-channel supply chain with free riding and servicecost sharing," International Journal of Production Economics, vol. 196, pp. 198-210, 2018.

[24] N. Yan, Y. Zhang, X. Xu, and Y. Gao, "Online finance with dual channels and bidirectional free-riding effect," International Journal of Production Economics, vol. 231, p. 107834, 2021.

[25] Z. Y. Pi, W. G. Fang, and B. F. Zhang, On the Implication of Free-Riding and Decision Bias to the Dual-Channel Operations, SSRN, Rochester, NY, USA, 2019.

[26] Y. He, H. Huang, and D. Li, "Inventory and pricing decisions for a dual-channel supply chain with deteriorating products," Operational Research, vol. 20, no. 3, pp. 1461-1503, 2020.

[27] Y. He, P. Zhang, and Y. Yao, "Unidirectional transshipment policies in a dual-channel supply chain," Economic Modelling, vol. 40, pp. 259-268, 2014.

[28] P. Zhang, Y. He, and X. Zhao, “"Preorder-online, pickup-instore" strategy for a dual-channel retailer," Transportation Research Part E: Logistics and Transportation Review, vol. 122, pp. 27-47, 2019.

[29] P. He, Y. He, and H. Xu, "Channel structure and pricing in a dual-channel closed-loop supply chain with government subsidy," International Journal of Production Economics, vol. 213, pp. 108-123, 2019.

[30] P. Zhang, Y. He, and C. Shi, "Retailer's channel structure choice: online channel, offline channel, or dual channels?" International Journal of Production Economics, vol. 191, pp. 37-50, 2017.

[31] L. L. Ren, Y. He, and H. F. Song, "Price and service competition of dual-channel supply chain with consumer returns," Discrete Dynamics in Nature and Society, vol. 2014, Article ID 565603, 10 pages, 2014.

[32] D. Yao and J. Liu, "Competitive pricing of mixed retail and e-tail distribution channels," Omega, vol. 33, no. 3, pp. 235-247, 2005.

[33] J. Chen, L. Liang, D.-Q. Yao, and S. Sun, "Price and quality decisions in dual-channel supply chains," European Journal of Operational Research, vol. 259, no. 3, pp. 935-948, 2017. 
[34] T. Xiao and J. Shi, "Pricing and supply priority in a dualchannel supply chain," European Journal of Operational Research, vol. 254, no. 3, pp. 813-823, 2016.

[35] H. Kurata, D.-Q. Yao, and J. J. Liu, "Pricing policies under direct vs. indirect channel competition and national vs. store brand competition," European Journal of Operational Research, vol. 180, no. 1, pp. 262-281, 2007.

[36] J. Zhao, X. Hou, Y. Guo, and J. Wei, "Pricing policies for complementary products in a dual-channel supply chain," Applied Mathematical Modelling, vol. 49, pp. 437-451, 2017.

[37] D. Konur and J. Geunes, "Supplier wholesale pricing for a retail chain: implications of centralized vs. decentralized retailing and procurement under quantity competition," Omega, vol. 65, pp. 98-110, 2016.

[38] F. Bernstein and A. Federgruen, "Pricing and replenishment strategies in a distribution system with competing retailers," Operations Research, vol. 51, no. 3, pp. 409-426, 2003.

[39] J. Chen, H. Zhang, and Y. Sun, "Implementing coordination contracts in a manufacturer Stackelberg dual-channel supply chain," Omega, vol. 40, no. 5, pp. 571-583, 2012. 